\title{
PROJETO SEGUNDO TEMPO: O FANZINE E A LEITURA DO ESPORTE EM BAIRROS VIOLENTOS
}

Victor Hugo Lima Monteiro

\section{RESUMO}

Este estudo tem o objetivo mostrar a verdadeira história de alguns alunos que estão inseridos em um dos pólos do Projeto Segundo Tempo (PST), no bairro do Guamá em Belém do Pará. Para isso, foram utilizadas para esta análise as conversas, as observações diárias, a linguagem utilizada, o esporte e o fanzine uma espécie de revista de produção independente que possibilitou maior aproximação e descontração para esses alunos discorrerem sobre a realidade que os permeia. A partir dos dados apreendidos, foram traçados novas possibilidades de intervenção através do projeto, permitindo um novo olhar sobre estes jovens e suas expectativas perante os professores, a sociedade e a vida.

Palavras-Chave: Esporte Educacional; Projeto Segundo Tempo; Violência; Realidade; Possibilidades.

\section{PROJECT SECOND TIME: THEW FINZINE AND READING OF SPORT IN VIOLENT NEIGHBORHOODS}

\begin{abstract}
This study aims to show the true story of some students who are placed in one of the poles of the Project Second Time (PST) in the neighborhood of Guamá in Belém do Pará. For this, we used this analysis to the talks, the daily observations, the language used, the sport and a sort of fanzine magazine production which allowed for more independent approach and fun for these students speaking of the reality behind them. From the data plotted seized new opportunities for intervention through the project, providing a new look at these people and their expectations before the teachers, society and life.
\end{abstract}

KEY-WORDS: Educational sport; Second Half Project, Violence, Reality, Possibilities. 


\section{INTRODUÇÃO}

$\mathrm{O} \mathrm{PST}^{1}$ tem por objetivo democratizar o acesso à prática esportiva para crianças e adolescente de sete a dezessete anos no contra turno escolar, preferencialmente aqueles expostos a risco social ${ }^{2}$ atualmente são beneficiados milhares de alunos em todo Brasil. Em Belém existem dezesseis pólos que somam três mil e duzentas vagas no total. No bairro do Guamá encontram-se apenas três abrangendo aproximadamente seiscentos jovens.

Considerando que o bairro em questão é um dos mais populosos da cidade e possui alto índice de criminalidade, a quantidade de pólos do PST pode ser considerada pequena para a realidade encontrada. Apesar disso, a presença do projeto neste espaço é de vital importância para a população do bairro, já que mantém esses jovens "afastados" mesmo que momentaneamente da realidade violenta do bairro quando estão em contato com o PST.

O objetivo básico deste projeto governamental é trabalhar o esporte educacional de qualidade, e conseqüentemente proporcionar a melhoria da auto-estima, a interação entre os jovens, a diminuição da violência, pois, entre outros aspectos fundamentais para a manutenção do bem-estar e da saúde destes alunos. Cada pólo do PST é composto por um coordenador e dois monitores, que devem trabalhar durante o ano no mínimo dois esportes coletivos e um individual oportunizando estes jovens vivenciar o esporte em toda sua amplitude.

O PST em si vai muito além do que foi apontado anteriormente. Já que, a intenção não é aprofundar a estrutura e a organização do PST em sua totalidade, mas, sim de visualizar as relações de ensino/aprendizagem e as interações professor/aluno em meio à realidade em que estes personagens estão inseridos com abordagens diferentes sobre o esporte e a utilização de ferramentas como o fanzine ${ }^{3}$, que possibilita novas formas de compreender os anseios e desejos deste público.

\footnotetext{
${ }^{1}$ Projeto Segundo Tempo.

${ }^{2}$ Todas as situações que expõe o ser humano a perigo constante. (Fonte: Política Nacional de Esporte. Brasília, 2005.)

${ }^{3}$ Formada pela junção das palavras inglesas fanatic e magazine, e tem o significado aproximado de "magazine do fã" ou "revista do fã".

Conexões: revista da Faculdade de Educação Física da UNICAMP, Campinas, v. 8, n. 3, p. 10-15, set./dez. 2010. ISSN: 1983-9030
} 
Adiante as relações e as metodologias utilizadas no dia-a-dia serão apresentadas e as novas possibilidades de intervenção na vida e na formação do caráter destes alunos, que em muitas oportunidades podem ser revoltados, agressivos e até marginalizados por parte da sociedade em que estão inseridos.

\section{O PST NO GUAMÁ: A história que não se conta}

No decorrer das atividades do PST e em especial no pólo em que foi realizado o presente estudo percebem-se as mais variadas formas de comportamento, emoções, ações e gestos dos alunos. Cada um tem a sua história e em muitas vezes ela não é explorada e trabalhada para melhoria das aulas e da conscientização deste jovem para com a sua realidade.

O esporte que os alunos conhecem e o que desejam é o que a mídia prega. Quando o professor quer trabalhar o esporte ou outro tipo de atividade de forma diferenciada e lúdica ele encontra grandes obstáculos, por parte daqueles alunos mais rebeldes que fazem de tudo para tumultuar as aulas e desafiar o professor com piadas, gestos, olhares e xingamentos. Cabe ao professor, transpor essas barreiras com o planejamento adequado de suas aulas e o conhecimento mais amplo de seus alunos, para poder ganhar a confiança destes e conseguir executar o seu trabalho com qualidade.

Visto que o disposto acima é fato e que o professor/monitor tem o poder de transformar e moldar o caráter destes jovens através do esporte educacional em conjunto com a arte, a cultura e a comunicação e fazendo-se sempre da criatividade como elemento indispensável em suas aulas, pois como já afirmara Taffarel ${ }^{1}$

[...] o ato criativo integra, em esforço único de busca do inédito, todas as capacidades da conduta humana afetiva, cognitiva e corporal. É nos atos de criação que se vislumbra o que há de verdadeiramente humano no homem.

Ou seja, é contribuir para a formação de caráter destes.

E para que essa transformação ocorra faz-se necessário primeiramente conhecer a realidade em que o aluno está inserido, e não somente as estatísticas de criminalidade 
do seu bairro. Com o intuito de descobrir novas formas de aproximação com aqueles alunos considerados "difíceis", foi proposta a confecção de um "rascunho" de fanzine em conjunto com a atividade que eles mais gostam que é, o futsal. O fanzine que é considerado por muitos como uma revista de produção independente e alternativa e segundo Nascimento ${ }^{2}$ "escreve-se o que pensa, sendo que os incômodos do dia-a-dia recebem um desenho literário de leitura marcante, alternativa e ousada". Ou seja, os alunos produziram a revista de sua vida contando a sua história e o resultado encontrado superou as expectativas não só do professor como a dos alunos.

Para a execução desta atividade primeiramente foi programado um torneio de futsal entre os alunos para depois da confecção dos fanzines, o que os manteve motivados a participar do processo. Para surpresa maior todos participaram da avaliação da atividade, onde foram feitas perguntas relativas às situações encontradas nas revistas obrigando estes jovens a analisarem a sua realidade e repensarem as suas atitudes dentro e fora do PST.

Para a confecção dos fanzines foram utilizados materiais como revistas, jornais, lápis de cor, canetinhas, cola, tesouras e uma folha de papel A4. Cada um dos alunos criou a sua capa, a contracapa, o nome de sua revista e o seu conteúdo. Todos os alunos sentiram-se livres para expor os seus problemas e as dificuldades que eles encontram na vida.

Analisando os fanzines e a avaliação, percebemos que a grande maioria dos alunos teve ou têm contato com drogas como a maconha e a cocaína. Alguns deles afirmaram que já cometeram assaltos, seja por necessidade ou por "curtição" com os mesmos denominaram. Foi comum identificar entre os jovens e no conteúdo de suas revistas a criminalidade e que a maioria não tem pai, outros são "brigados" com a mãe e até mesmo aqueles que não têm pai e nem mãe.

Adolescentes? Quantos jogados nas mãos do tráfico? Jovens sem acesso à cultura, ao esporte, condenados ao trabalho. Desde cedo vivenciando a violência que os rodeia em seu cotidiano. Sem perspectivas reais de sonhar com um mundo que lhe seja justo e solidário e, em tantos casos, tampouco esperançoso de uma vida longa. ${ }^{3}$

Conexões: revista da Faculdade de Educação Física da UNICAMP, Campinas, v. 8, n. 3, p. 10-15, set./dez. 2010.

ISSN: 1983-9030 
Muitos fanzines foram feitos de forma bem estruturada mostrando a relação da realidade vivida, o sonho, e o consumo. A maioria dos alunos relatou que a violência está no seu dia-a-dia, o que foi de fácil percepção pelo próprio comportamento destes uns com os outros e com o professor. Depoimentos como os dos alunos "A" e "B" respectivamente "minha vida é cheia de bomba e bola" e o "esse projeto é minha segunda casa!" foram fáceis de encontrar em suas produções.

Foi perguntado também, sobre a relação professor/aluno existente no PST e a resposta encontrada foi positiva. Os alunos disseram que admiram e respeitam o professor (coordenador/monitores), e que a maneira como esses ministram as aulas é boa. No entanto, eles sempre querem apenas jogar futsal, o que é fruto do estilo daquele professor que "dá a bola" e senta para ler o seu jornal, realidade esta já mencionada por Libâneo " "[...] infelizmente há também muitos professores improvisados e irresponsáveis, que não conseguem ver o alcance e a importância do seu trabalho".

Com os relatos supracitados fica evidente a importância do PST para esses alunos e para os estudantes de educação física, que obtém experiências únicas e que lhes servirão para o resto de sua carreira como professor e para seu crescimento como ser humano.

\section{UMA BREVE CONSIDERAÇÃO}

Considerando tudo o que foi abordado neste estudo reafirma-se a importância de projetos sociais como o PST, onde os alunos são apresentados a práticas esportivas que visam o bem-estar e a saúde em conjunto com ações sociais retirando ou preservando estes jovens de situações de risco como o uso de drogas, o envolvimento com a criminalidade e outros entraves que venham atrapalhar o seu desenvolvimento pleno.

A experiência com a confecção dos fanzines estimulou a criatividade não só dos alunos, e ajudou os professores na aproximação com alunos considerados de difícil trato. Atividades como essa, nos projetos só tem a colaborar para o enriquecimento 
das aulas, e oportuniza aos alunos a expressarem os seus sentimentos de maneira simples e direta.

Os professores devem apresentar sempre que possível as modalidades esportivas que os alunos não têm contato diariamente como a ginástica, o xadrez e as lutas como a capoeira, o judô, karatê e o boxe pregando suas filosofias e os seus movimentos básicos para apresentar estes jovens novas oportunidades de vivenciar os esportes que não estão em seu cotidiano. As modalidades esportivas como o futsal, o vôlei, o handebol e o basquete sempre devem ser trabalhadas de modo que todos os alunos tenham a capacidade de vivenciá-las, com prazer (lúdico) e não privilegiar a técnica ou a habilidade dos mais aptos.

Em síntese os professores devem primar por atividades que proporcionem acima de tudo o prazer para seus praticantes, em conjunto com atividades culturais, usando sempre a criatividade para que possa superar as expectativas de cada aluno, sempre pensando em seu desenvolvimento pleno.

\section{REFERÊNCIAS}

${ }^{1}$ TAFFAREL, C. N. Z. Criatividade nas aulas de Educação Física. Rio de Janeiro: Ao Livro Técnico, 1985.

2 NASCIMENTO, M. E. A escrita dos fanzines. In: CONGRESSO DE LETRAS, 5., 2008, São Gonçalo. Anais... São Gonçalo: UERJ, 2008.

${ }^{3}$ OLIVEIRA, A. A. B.; PERIM, G. L. (Org.). Fundamentos pedagógicos para o Programa Segundo Tempo. Brasília: Ministério dos Esportes; Porto Alegre: UFRGS, 2008.

${ }^{4}$ GHIRALDELLI JR., P. Educação Física progressista: a pedagogia crítico-social dos conteúdos e Educação Física brasileira. 6. ed. São Paulo: Loyola, 1988. 